\title{
Identification of Host Fruit Volatiles from Domestic Apple (Malus domestica), Native Black Hawthorn (Crataegus douglasii) and Introduced Ornamental Hawthorn (C. monogyna) Attractive to Rhagoletis pomonella Flies from the Western United States
}

\author{
Dong H. Cha • Wee L. Yee • Robert B. Goughnour • \\ Sheina B. Sim • Thomas H. Q. Powell • \\ Jeffrey L. Feder • Charles E. Linn Jr
}

Received: 29 September 2011 /Revised: 3 February 2012/Accepted: 19 February 2012 /Published online: 8 March 2012

(C) Springer Science+Business Media, LLC 2012

\begin{abstract}
The apple maggot fly, Rhagoletis pomonella, infests apple (Malus domestica) and hawthorn species (most notably the downy hawthorn, Crataegus mollis) in the eastern USA. Evidence suggests that the fly was introduced into the western USA sometime in the last 60 years. In addition to apple, $R$. pomonella also infests two species of hawthorns in the western USA as major hosts: the native black hawthorn (C. douglasii) and the introduced ornamental English hawthorn, C. monogyna. Apple and downy hawthorn-origin flies in the eastern USA use volatile blends emitted from the surface of their respective ripening fruit to find and discriminate among host trees. To test whether the same is true for western flies, we used coupled gas chromatography and electroantennographic detection (GC-EAD) and developed a 7-component apple fruit blend for western apple-origin flies, an 8-component black hawthorn
\end{abstract}

D. H. Cha $\cdot$ C. E. Linn Jr $(\bowtie)$

Department of Entomology, NYS Agricultural Experiment Station, Cornell University,

Geneva, NY 14456, USA

e-mail: CEL1@cornell.edu

W. L. Yee $\cdot$ R. B. Goughnour

USDA-ARS Yakima Agricultural Research Laboratory,

Wapato, WA 98951, USA

S. B. Sim • T. H. Q. Powell • J. L. Feder

Department of Biological Sciences, University of Notre Dame,

Notre Dame, IN 46656, USA

Present Address:

D. H. Cha

USDA-ARS Yakima Agricultural Research Laboratory,

Wapato, WA 98951, USA fruit blend for flies infesting $C$. douglasii, and a 9-component ornamental hawthorn blend for flies from C. monogyna. Crataegus douglasii and C. monogyna-origin flies showed similar levels of upwind directed flight to their respective natal synthetic fruit blends in flight tunnel assays compared to whole fruit adsorbent extracts, indicating that the blends contain all the behaviorally relevant fruit volatiles to induce maximal response levels. The black and ornamental hawthorn blends shared four compounds in common including 3-methylbutan1-ol, which appears to be a key volatile for $R$. pomonella populations in the eastern, southern, and western USA that show a preference for fruit from different Crataegus species. However, the blends also differed from one another and from domesticated apple in several respects that make it possible that western $R$. pomonella flies behaviorally discriminate among fruit volatiles and form ecologically differentiated host races, as is the case for eastern apple and hawthorn flies.

Keywords Apple maggot fly - Olfaction · Fruit odor discrimination · Flight tunnel $\cdot$ Host races

\section{Introduction}

The apple maggot, Rhagoletis pomonella (Walsh) (Diptera: Tephritidae) is a model system for sympatric ecologicallybased speciation via host plant shifting for phytophagous insects (Feder, 1998; Funk et al., 2002). In particular, the shift of the fly from its native host downy hawthorn, Crataegus mollis Scheele (Rosales: Rosaceae), to introduced Eurasian apple, Malus domestica Mill. (Rosales: Rosaceae) in the northeastern USA 
in the mid-1800s is often cited as an example of sympatric host race formation in the absence of geographic isolation and in the face of gene flow (Bush, 1966, 1969; Berlocher et al., 1993; Berlocher and Feder, 2002; Coyne and Orr, 2004). The shift of $R$. pomonella to apple also resulted in the fly becoming a major pest of commercial apple production in the growing regions of the northeast and Michigan.

The geographic range of the apple maggot fly is not limited to the northeastern and mid-western USA, however. In the late 1970s, R. pomonella was detected in the Pacific Northwest. Here, the fly costs apple growers tens of millions of dollars annually in monitoring, quarantine, and control, as there is a zero infestation policy for apple fruit export to foreign and domestic markets, a $\$ 1.5$ billion a year industry in Washington State alone (National Agricultural Statistics Service, 2009). It generally is believed that the apple infesting race of R. pomonella was brought to the Pacific Northwest from the eastern USA via larval-infested apples sometime in the 1950s (AliNiazee and Westcott, 1987; Brunner, 1987; Tracewski et al., 1987). It is thought that the introduction probably occurred around the Portland, Oregon area where the first confirmed report of apple-infesting flies was made in 1979 (AliNiazee and Penrose, 1981). The fly then spread latitudinally up and down Oregon and Washington along the western side of the Cascade Mountains, reaching as far north as British Columbia, Canada and as far south as northern California. The fly also has encroached into commercial apple growing regions in central Washington, possibly by moving up the Columbia River Gorge.

Rhagoletis pomonella also infests hawthorns in the Pacific Northwest, including native black hawthorn, $C$. douglasii, and the introduced English ornamental hawthorn, C. monogyna (Yee and Goughnour, 2008), the latter possibly brought to the region following World War I. If apple flies were introduced from the eastern to the western USA, then these hawthorninfesting populations represent host shifts of $R$. pomonella from apple back to hawthorn in the Pacific Northwest. Consistent with the introduction and host shift hypothesis, $R$. pomonella was first reported infesting the host $C$. douglasii in central Washington in 2003 (Yee, 2008). Although not an overly abundant plant west of the Cascade Mountains, the range of fruiting black hawthorn is fairly extensive along rivers and streams through the northwest, including central Washington. Thus, if $R$. pomonella has always existed on black hawthorn in the west, then it should have been detected infesting $C$. douglasii in central Washington prior to 2003, given the extensive annual monitoring program to control the fly performed by the Washington State Department of Agriculture begun in 1981 (Yee, 2008; Yee and Goughnour, 2008). Hawthorns would, therefore, appear to represent an alternate host to introduced apple-infesting flies in the West, and black hawthorn flies now in central Washington likely pose a new and serious threat to the apple industry. In addition, it is possible that black hawthorn and ornamental hawthorn populations of $R$. pomonella may also represent new races of the fly in the Pacific Northwest.

In the eastern USA, apple and downy hawthorn-infesting flies use volatile compounds released from the surface of ripening fruit as key olfactory cues to find and discriminate among host plants (Linn et al., 2003, 2004, 2005a,b; Dambroski et al., 2005; Forbes et al., 2005). Host fruit odor discrimination is important because the eastern apple and downy hawthornorigin flies mate exclusively on or near the fruit of their respective host plants (Prokopy et al., 1971, 1972; Feder et al., 1994). Hence, differences in host plant choice translate directly to mate choice, generating premating reproductive isolation between the apple and downy hawthorn host races (Feder et al., 1994; Linn et al., 2003; Forbes et al., 2005; Forbes and Feder, 2006). In flight tunnel assays and field trapping studies, we found that the eastern apple and downy hawthorn host races of $R$. pomonella preferentially orient to the fruit volatile blends of their respective native host fruit relative to non-natal volatiles (i.e., apple flies positively respond and fly to a synthetic volatile blend developed for apple fruit and are not overly attracted to downy hawthorn fruit volatiles, and the reverse for downy hawthorn flies) (Linn et al., 2003, 2004, 2005a,b; Forbes et al., 2005; Dambroski et al., 2005; Forbes and Feder, 2006; Feder and Forbes, 2007, 2008).

Here, we present results of studies on the chemical ecology of western populations of $R$. pomonella by developing synthetic volatile blends for the black hawthorn, $C$. douglasii, and the introduced ornamental hawthorn, C. monogyna, through a combination of gas chromatography/electroantennographic detection (GC-EAD) analysis of both solid phase microextraction (SPME) and adsorbent samples collected from fruit headspace. Our objective was to use these synthetic blends to behaviorally test flies in flight tunnel assays and field trapping studies (the latter to be reported elsewhere) to establish the origins of western populations and to determine whether sympatric host races of $R$. pomonella exist on apple and hawthorns in the Pacific Northwest. We also investigated new formulations of the eastern apple blend by adding additional ester volatiles to the standard 5-component blend of Zhang et al. (1999). We conducted the latter studies based on reports from field trapping trials in Washington that imply that the standard eastern apple blend may not be as attractive to western as eastern flies (Yee et al., 2005).

\section{Methods and Materials}

In the following sections, we outline the methods of chemical and behavioral analysis that were used to develop and test synthetic volatile fruit odor blends for western apple, black hawthorn, and ornamental hawthorn-infesting flies. These methods are the same as those that we have successfully used in the past to construct synthetic blends for eastern and southern 
R. pomonella populations. Complete details of the procedures can be found in Zhang et al. (1999), Nojima et al. (2003a,b), and Cha et al. (2011a,b).

Insects Flies used in the study were collected as larvae in infested host fruit and reared to the pupal stage in the laboratory at Washington State University in Vancouver, WA using standard $R$. pomonella husbandry techniques (Neilson and McAllan, 1965; Linn et al., 2003; Dambroski and Feder, 2007). Pupae were shipped to the Geneva, NY, lab, and upon eclosion adult flies were kept in a walk-in environmental chamber at $23-24^{\circ} \mathrm{C}, 16 \mathrm{~L}: 8 \mathrm{D}$ photoperiod, and $65-70 \%$ r.h., on an artificial diet made of water, sugar, vitamins, casein hydrolysate, and salt mixture prior to testing (Fein et al., 1982). Western flies tested in the study came from four different apple sites, three different black hawthorn sites, and one ornamental hawthorn site in Washington (Table 1). Eastern apple-origin $R$. pomonella tested in certain GC-EAD analyses came from a laboratory colony maintained on Red Delicious apples at the Agricultural Experiment Station in Geneva, NY (Neilson and McAllan, 1965; Linn et al., 2003). Eastern apple flies collected and reared from a field site in Grant, MI and eastern downy hawthorn flies from two sites in Grant and Fennville, MI were also tested in certain GC-EAD analyses. Adult flies at 0-7 and 10-21-d-old were used for GC-EAD analyses and flight-tunnel behavior tests, respectively.

Fruit Black hawthorn fruit (C. douglasii) used for the GCEAD analysis were collected from Wenas, WA, in 2007 (Table 1). Ornamental hawthorn fruit were collected from the Burnt Bridge Creek Greenway site in Vancouver, WA in 2008 (Table 1). Fruit collections were made in the field and shipped overnight to the Cornell Laboratory for volatile characterization. Red delicious fruit were collected from an Experiment Station apple orchard in Geneva, NY in 2007.
Headspace Volatile Sampling Adsorbent samples of fruit headspace volatiles were made from whole fruit using $2.4 \mathrm{~L}$ closed volatile collection chambers (ARS, Inc., Gainesville, FL, USA; Glass Shop, Cornell University, Ithaca, NY, USA). Field collected fruits (500-800 $\mathrm{ml}$ in volume) were gently cleaned with distilled water, thoroughly dried, and then immediately put into a collection chamber. Clean air was pushed into the chamber at $0.7 \mathrm{Lmin}^{-1}$, and volatiles were pushed out through volatile traps (activated charcoal filters, ORBO32small, Supelco Inc., Bellefonte, PA, USA) on the bottom of the chamber. For each sample of fruit, adsorbent collections were made over a 5-d-period. Volatiles were eluted with $500 \mu \mathrm{l}$ methylene chloride every $24 \mathrm{~h}$ and combined across the five collection days. The combined extract was kept at $-20^{\circ} \mathrm{C}$ and subjected to GC-EAD, GC-MS (mass spectrometry), and flight tunnel analyses.

For the quick evaluation of fruit headspace volatiles, SPME sampling also was performed using a glass jar (500 ml) with Teflon liner screwcap (Wheaton, Milliville, NJ, USA), containing ca. $150 \mathrm{~g}$ of fruit. A carboxen-polydimethylsiloxane-coated SPME fiber (film thickness $85 \mu \mathrm{m}$; Supelco) was conditioned in the GC injector $\left(280^{\circ} \mathrm{C}\right)$ for $5 \mathrm{~min}$, and then passed through the small hole on the cap into the headspace of the jar. After a 10 to 20-min-exposure, collected volatiles were subjected to GC-EAD and GC-MS analysis.

Coupled Gas Chromatographic-Electroantennographic Detection (GC-EAD) Analysis Coupled GC-EAD analysis was performed using a Hewlett Packard 5890 Series II gas chromatograph equipped with a non-polar EC-1 capillary column $(30 \mathrm{~m} \times 0.25 \mathrm{~mm}$ diam, $0.25 \mu \mathrm{m}$ film thickness; Alltech Associates, Inc., Deerfield, IL, USA) or a Shimadzu GC-17A gas chromatograph equipped with a polar EC-Wax Econo-Cap capillary column $(30 \mathrm{~m} \times 0.25 \mathrm{~mm}$ diam, $0.25 \mu \mathrm{m}$ film thickness; Alltech) in the splitless mode. Injector and
Table 1 Host plant sites (latitude (Lat.) $[\mathrm{N}]$ and longitude (Long.) [W] in deg. and min.) sampled in the study. WA=Washington state, $\mathrm{MI}=$ Michigan, $\mathrm{NY}=\mathrm{New}$ York

\begin{tabular}{llrr}
\hline Host plant & Location & Lat. & Long. \\
\hline Western apple & Puyallup, WA & 47.11 & 122.18 \\
& Vancouver, WA (Burnt Bridge Creek Greenway) & 45.18 & 122.36 \\
& Skamania, WA (St. Cloud Park, Hyw. 14) & 45.35 & 122.06 \\
& Wenas, WA & 46.87 & 122.67 \\
Eastern apple & Geneva, NY & 42.52 & 77.00 \\
& Grant, MI & 43.35 & 85.86 \\
Western black hawthorn & Vancouver, WA (Burnt Bridge Creek Greenway) & 45.18 & 122.36 \\
& Skamania, WA (St. Cloud Park, Hyw. 14) & 45.35 & 122.06 \\
& Wenas, WA & 46.87 & 122.67 \\
Western ornamental hawthorn & Puyallup, WA & 47.11 & 122.18 \\
& Vancouver, WA (Burnt Bridge Creek Greenway) & 45.18 & 122.36 \\
Eastern downy hawthorn & Grant, MI & 43.35 & 85.86 \\
& Fennville, MI (62nd St.) & 42.36 & 86.09 \\
\hline
\end{tabular}


detector temperatures were set at $280^{\circ} \mathrm{C}$ and $270^{\circ} \mathrm{C}$, respectively. The oven temperature was programmed for $5 \mathrm{~min}$ at $40^{\circ} \mathrm{C}$, and $5^{\circ} \mathrm{C} \mathrm{m^{-1 }}$ increase to $250^{\circ} \mathrm{C}$ and then held for $5 \mathrm{~min}$. Whole head preparations were made of individual flies for GC-EAD analysis (Nojima et al. 2003a). The antennal holder was placed inside a humidified condenser and maintained at $5^{\circ} \mathrm{C}$. The output signal from the antenna was recorded on an HP 3390A integrator.

Chemical Analysis GC-MS was carried out as previously described (Zhang et al., 1999; Nojima et al., 2003a,b; Cha et al., 2011a,b) with a Shimadzu GCMS-QP5050A quadrupole mass spectrometer in EI (at $70 \mathrm{eV})$ scan mode coupled with a Shimadzu GC-17A equipped with a nonpolar DB-1 ms capillary column or a polar EC-Wax Econo-Cap capillary column. Helium was the carrier gas (54 kPa at $1.1 \mathrm{ml} / \mathrm{min})$. The GC conditions and temperature program were as for the GC-EAD analyses. The interface temperature was set at $260^{\circ} \mathrm{C}$. Volatile compounds were identified by comparison of chromatographic retention times and mass spectra with those of authentic standards analyzed on the same instrument. The identification was further verified by antennal responses in the GC-EAD analyses to the standard compounds. Quantification of the relative ratio of the EAD active compounds was made from the adsorbent collection based on total ion abundances from GC/MS analyses according to the standard curves made from each authentic sample.

Chemicals Pentyl hexanoate, hexyl butanoate, butyl hexanoate, propyl hexanoate, pentyl butanoate, butyl butanoate, 3-methylbutan-1-ol, D-limonene, pentyl acetate, hexyl acetate, ethyl heptanoate, isoamyl butyrate, isoamyl isobutyrate, isoamyl propionate, $(Z)$-3-hexenyl acetate, hexyl isobutyrate (purities $\geq 98 \%$ ), hexyl propionate, hexyl hexanoate (purities $\geq$ 97\%), nonanal, and linalool (purities $\geq 95 \%$ ) were purchased from Sigma-Aldrich (St. Louis, MO, USA). The compound 2-methylbutyl 2-methylbutyrate ( $\geq 90 \%$ ) was purchased from TCI America (Portland, OR, USA). The compound (3E)-4,8dimethyl-1,3,7-nonatriene (DMNT) was synthesized by oxidation of geraniol and then by Wittig reaction with methylenetriphenylphosphorane (Greenwald et al., 1963) and purified ( $>97 \%$ with $>97 \% E$-isomer by GC-MS) using flash chromatography on silica gel. The synthesis product was eluted with hexane and then subjected to Kugelrohr distillation (b.p. $\sim 60$ $70^{\circ} \mathrm{C} / 3.0 \mathrm{mmHg}$ ) to remove non-volatile impurities, such as traces of silica.

Synthetic Blends and Flight Tunnel Sources We prepared the black and ornamental hawthorn synthetic blends as listed in Table 2. As in our previous flight tunnel studies (Zhang et al., 1999; Nojima et al., 2003a,b; Linn et al., 2003), we applied $200 \mu \mathrm{l}$ of synthetic blend $(1 \mu \mathrm{g} / \mu \mathrm{l})$ to a red rubber septum (hexane-washed; Thomas Scientific, Swedesboro, NJ, Cat. no. 1780J07). The $200 \mu \mathrm{g}$ dose was selected to provide a comparison with previous studies showing maximal levels of flight behavior with other Rhagoletis populations (Zhang et al., 1999; Linn et al., 2003; Nojima et al., 2003a,b). The septum sources were prepared $60 \mathrm{~min}$ prior to a test and were clipped onto the bottom of a $7.5 \mathrm{~cm}$ red plastic sphere (Gempler's Inc., Mt. Horeb, WI, USA). Fresh sources and red spheres were used for each replicate. Preliminary experiments showed that a $200 \mu \mathrm{g}$ septum can be used in the tunnel for $6 \mathrm{~h}$ without a loss in response levels, a period significantly longer than any single replicate. To test the adsorbent extracts in the flight tunnel, we adjusted (either by diluting with hexane or concentrated under a gentle stream of nitrogen gas) the concentration (GC peak size) of GC-EAD active volatiles to become similar with the GC profiles of the synthetic blend at $1 \mu \mathrm{g} / \mu \mathrm{l}$ concentration, and applied $200 \mu \mathrm{l}$ of the extract to a rubber septum.

Modified Synthetic Blends To identify key volatiles involved in attraction or acting as behavioral antagonists to black and ornamental hawthorn-origin flies, we prepared modified blends by subtracting volatile compounds from the candidate blends selected on the basis of consistent EAD responses (Table 2). The modified blends were prepared so that each compound was always in the same amount as in the corresponding complete blends, thus eliminating the potential effect of variation in concentration. For flight tunnel testing we applied $200 \mu \mathrm{l}$ of the modified blend to a rubber septum. The concentration of each modified blend is listed in Table 2 .

Flight Tunnel The response of flies to host fruit volatiles was measured in a sustained-flight tunnel (Nojima et al., 2003a). Flight-tunnel conditions were $23-24^{\circ} \mathrm{C}, 50-70 \%$ r.h., $35 \mathrm{~cm} /$ sec wind speed, $1500 \mathrm{~lx}$ light intensity. We used sexually mature adult flies (males and females) that were 10-21-d-old (post-eclosion) and had never been previously exposed to the fruit volatile blends (i.e., fruit odor-naïve flies). These flies were tested during the $3 \mathrm{rd}$ to 11 th $\mathrm{hr}$ of the $16 \mathrm{~h}$ photophase period in the flight tunnel. Flies were selected from holding cages located in a separate, environmentally controlled room, placed singly in glass vials, taken to the room housing the flight-tunnel, and then allowed to acclimate for at least $30 \mathrm{~min}$ before testing. Individual flies were transferred to a screen holding cage, which was then placed on a release stand such that the open end of the cage faced upwind at a distance of $1 \mathrm{~m}$ to the odor source. Flies were given $1 \mathrm{~min}$ to respond, and scored by a human observer for the following two behaviors: 1) no response $=$ fly did not take flight, but remained in the release cage, generally walking and grooming or flew for a short distance to the side of the flight tunnel; and 2) upwinddirected flight $=$ fly faced upwind, walked to the edge of the release cage (100 cm from source), and took flight and initiated 


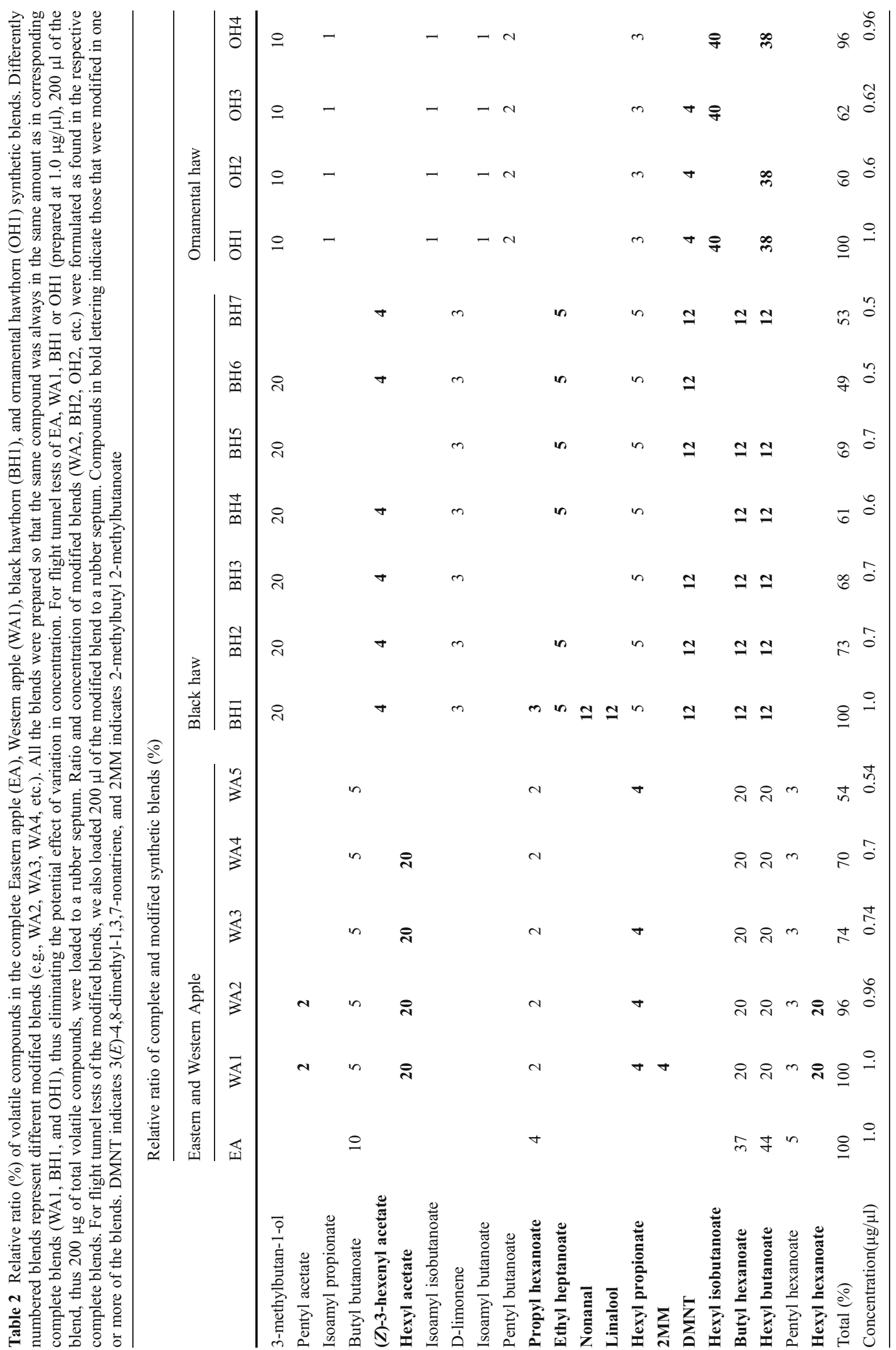


upwind oriented flight in the odor plume. An upwind flight response was scored as positive if the fly exhibited plumeoriented flight for at least $50 \mathrm{~cm}$ toward the sphere [we previously showed that at this distance flies are not attracted to the red sphere alone with no odor source (Linn et al., 2003)]. In the following sections, 'agonist' volatiles refer to those compounds that contributed to the positive upwind directed flight response to a particular blend, and 'antagonist' refers to a non-natal host volatile that, when added to a blend, resulted in a significant reduction in upwind directed flights.

For each of the host plants, our experimental protocol involved first testing adsorbent extracts in the flight tunnel, with the expectation that response levels should be high, thus indicating that the behaviorally active blend was contained in the extract, and that no potential deterrent compounds were present, such as might occur with over-ripe or rotting fruit. Given a high response level to the extract, we then tested the candidate synthetic blends that were selected from the GCEAD profiles based on the consistency of the responses over the majority ( $>75 \%)$ of the profiles. Again, the expectation was that response levels should be high and equivalent to those observed with the extracts. We then tested flies to modified blends that had volatiles subtracted or added to the complete blends to determine whether all of the compounds identified from the GC-EAD profiles were required for maximal response (upwind-directed flight). For each extract or synthetic blend, different sets of flies were tested as the flies became available from field collections of infested fruit. For the experiments with apple and black hawthorn-origin flies, each treatment involved a separate group of flies, but for ornamental hawthorn flies, the same group of 25 individuals was tested to all of the treatments. In previous studies, we showed that $R$. pomonella flies can be repeatedly tested without affecting odor preference as displayed in the flight tunnel (Dambroski et al., 2005). Differences in the frequency of upwind flight were compared using Fisher's Exact Test in R ( R development core team, Vienna, Austria).

\section{Results}

Identification of Fruit Volatiles for Western Apple-Origin Flies Western apple-origin flies were tested for GC-EAD activity using adsorbent extracts from Red Delicious apples from orchards at the Experiment Station in Geneva, NY, the same source of apples used in earlier volatile identifications for eastern apple-origin flies (Zhang et al., 1999). A total of 25 antennal pairs (1-6 replicate runs/pair) were used for the analysis. The flies tested were from Vancouver, Puyallup, Skamania, and Wenas, WA. Figure 1a shows a GC-EAD trace from the antenna of a western apple-origin fly from the Vancouver, WA site to the Red Delicious extract. The corresponding active compounds were identified as (Ia) pentyl acetate, (IIa) butyl
Fig. 1 Simultaneously recorded GC-EAD responses of adult western apple, black hawthorn, and ornamental hawthorn fly antennae to adsorbent samples of volatiles released from apple, black hawthorn and ornamental hawthorn, respectively. Different traces indicate GC and antennal response (EAG) of (a) western apple-origin flies to apple fruit adsorbent samples, (b) western black hawthorn-origin flies to black hawthorn fruit adsorbent samples, and (c) western ornamental hawthorn-origin flies to ornamental hawthorn fruit adsorbent samples. DMNT indicates $(3 E)$-4,8-dimethyl-1,3,7-nonatriene

butanoate, (IIIa) hexyl acetate, (IVa) propyl hexanoate, (Va) hexyl propionate, (VIa) 2-methylbutyl 2-methylbutanoate (VIIa) butyl hexanoate, (VIIIa) hexyl butanoate, (IXa) pentyl hexanoate, and (Xa) hexyl hexanoate. The relative ratio of the EAD active compounds in the red delicious extract estimated with GC-MS are listed in Table 2.

Identification of Fruit Volatiles from Western Black Hawthorn Western black hawthorn (C. douglasii) fruit were analyzed from four samples collected from Wenas, WA in 2007, two in July and two in August. The August samples contained greater quantities of volatiles and were the focus of all our subsequent analyses. A total of 20 antennal pairs (1-4 replicate runs/pair) of black hawthorn-origin flies originating from Vancouver, Skamania, and Wenas, WA were used for the GC-EAD analysis. Figure $1 \mathrm{~b}$ shows a GC-EAD recording from the antennae of a Vancouver, WA black hawthorn-origin fly exposed to the whole fruit extract at a stage when $>90 \%$ of the fruit was ripe. We note that whereas the traces indicate the presence of some unidentified peaks with EAD responses, these responses were not present in the majority $(>75 \%)$ of GC-EAD runs examined. The corresponding active compounds were identified as (Ib) 3-methylbutan-1-ol, (IIb) (Z)3-hexenyl acetate, (IIIb) D-limonene, (IVb) propyl hexanoate, (Vb) ethyl heptanoate, (VIb) nonanal, (VIIb) linalool, (VIIIb) hexyl propionate, (IXb) DMNT, (Xb) butyl hexanoate, and (XIb) hexyl butanoate. All of the compounds in Fig. 1b were consistently found in the fruit collected from the Wenas, WA location. The relative ratio of the $\mathrm{EAD}$ active compounds in $C$. douglasii estimated with GC-FID and GC-MS are listed in Table 2.

Identification of Fruit Volatiles from Western Ornamental Hawthorn Western ornamental hawthorn fruit (C. monogyna) collected in 2008 from the Burnt Bridge Creek Greenway, Vancouver, WA site were analyzed with GC-EAD using a single antennal pair from an ornamental haw-origin fly collected from the same site (5 replicate runs). However, for comparison, apple-origin flies from the Geneva, NY, Lab colony ( 2 antennal pairs, 3 replicates/pair), apple-origin flies from Grant, MI (1 antennal pair, 3 replicates), downy hawthorn-origin flies from Grant, MI (2 pair, 3 replicates/pair) and Fennville, MI ( 7 pair, 7 replicates/pair), and black hawthorn-origin flies from Vancouver, WA (2 pair, 4 
(a) Apple

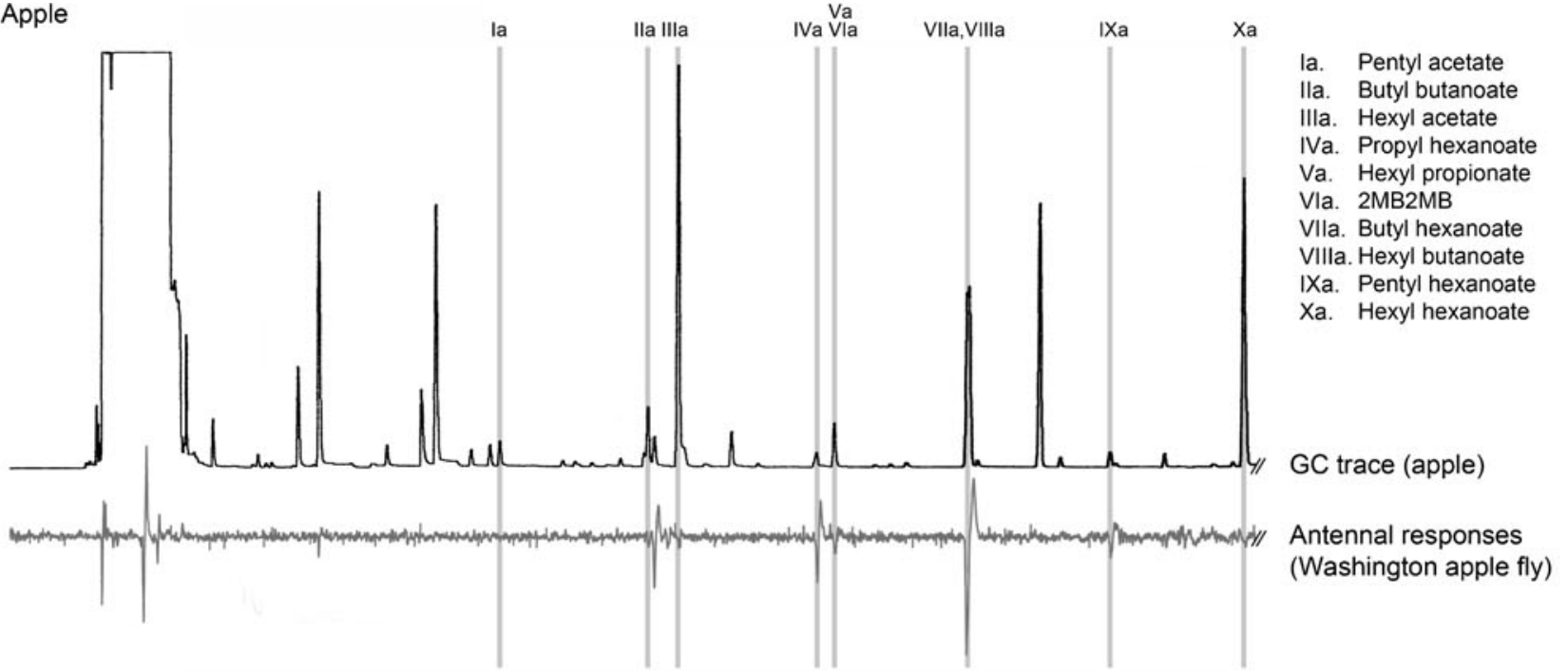

(b) Black Hawthorn

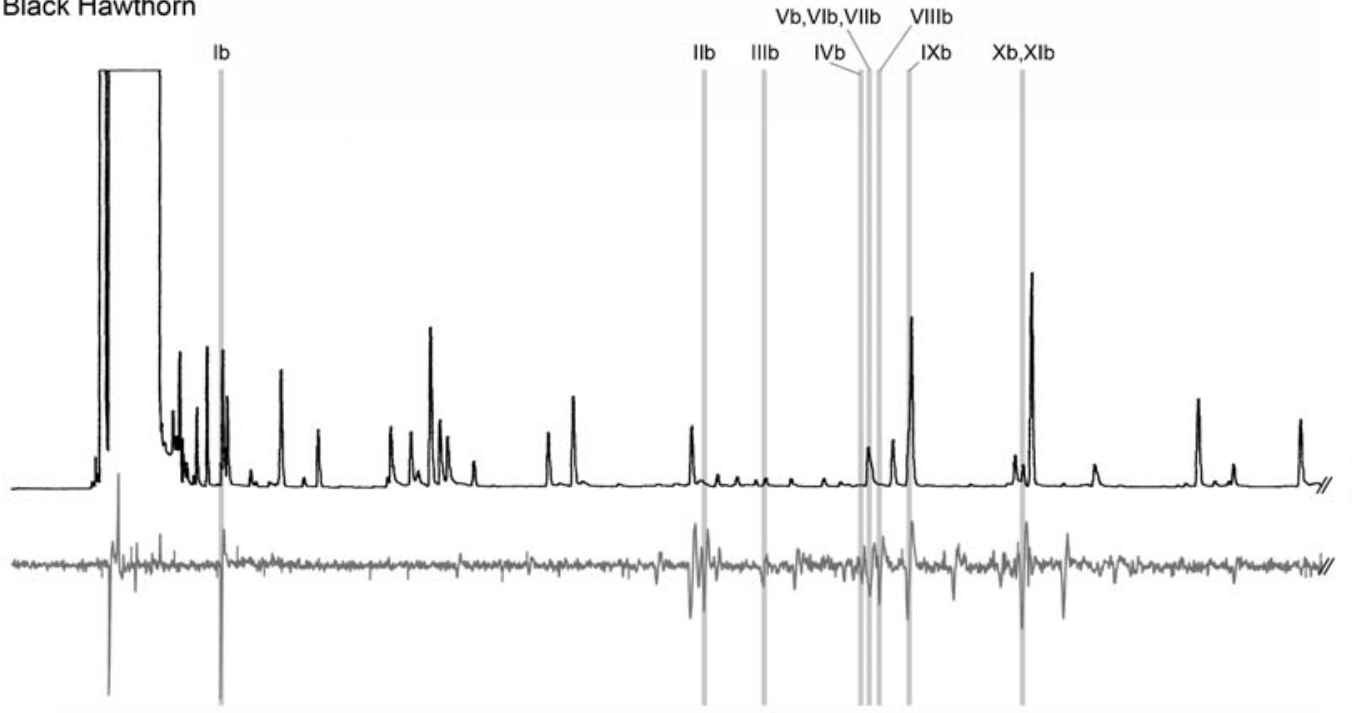

$$
\begin{aligned}
& \text { Ib. 3-methylbutan-1-ol } \\
& \text { IIb. (Z)-3-hexenyl acetate } \\
& \text { IIIb. D-limonene } \\
& \text { IVb. Propyl hexanoate } \\
& \text { Vb. Ethyl heptanoate } \\
& \text { VIb. Nonanal } \\
& \text { VIlb. Linalool } \\
& \text { VIIIb. Hexyl propionate } \\
& \text { IXb. DMNT } \\
& \text { Xb. Butyl hexanoate } \\
& \text { XIb. Hexyl butanoate }
\end{aligned}
$$

$\mathrm{GC}$ trace

(Black hawthorn)

Antennal responses

(Black hawthorn fly)

(c) Ornamental Hawthorn

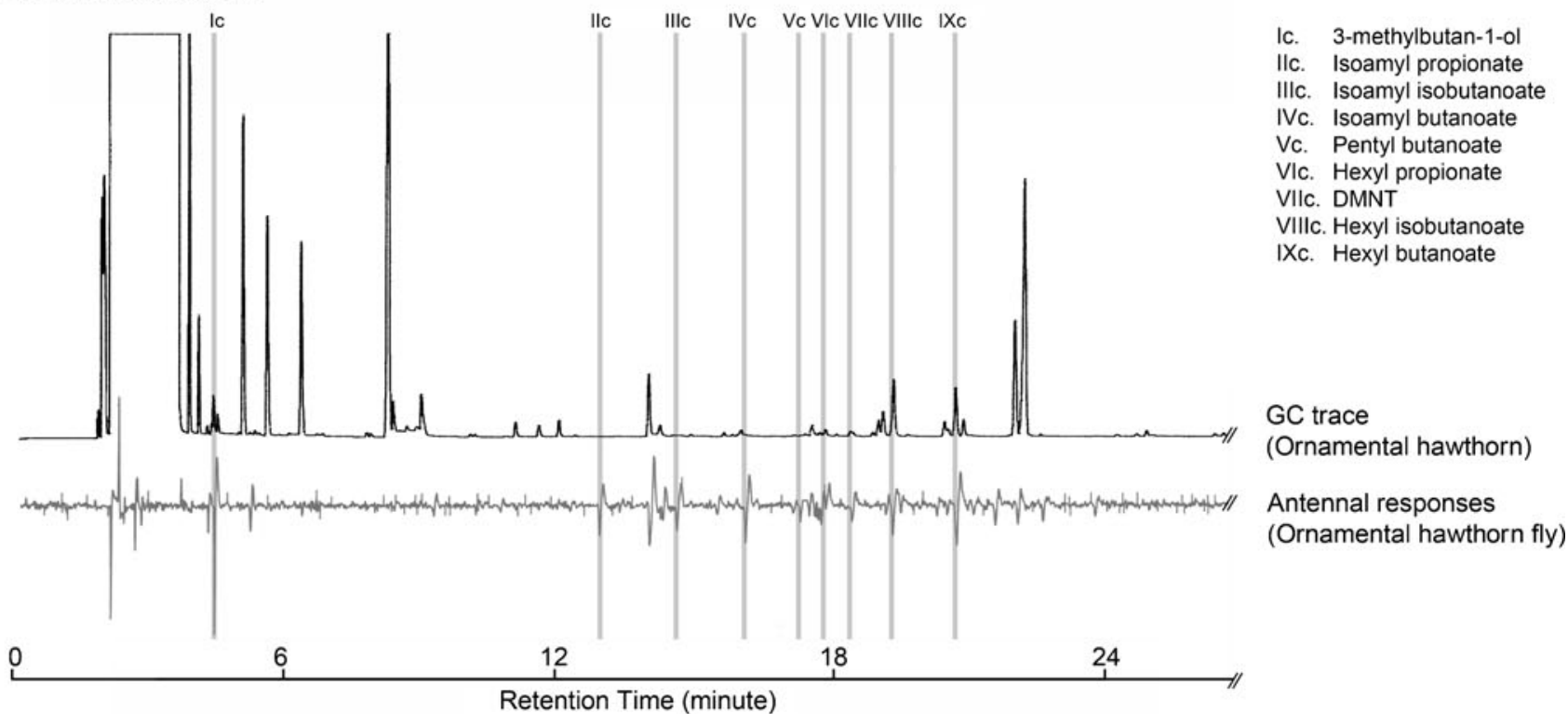

Retention Time (minute) 
replicates/pair) also were used to confirm the ornamental hawthorn fruit volatile identification. Figure 1c shows a GCEAD recording from the antennae of a western ornamental hawthorn-origin fly from Vancouver, WA exposed to an adsorbent whole fruit extract of $C$. monogyna from the same site. The corresponding active compounds were identified as (Ic) 3-methylbutan-1-ol, (IIc) isoamyl propionate, (IIIc) isoamyl isobutanoate, (IVc) isoamyl butanoate, (Vc) pentyl butanoate, (VIc), hexyl propionate, (VIIc) DMNT, (VIIIc) hexyl isobutanoate, and (IXc) hexyl butanoate. The relative ratio of the EAD active compounds in C. monogyna estimated with GCFID and GC-MS, are listed in Table 2.

Behavioral Responses of Western Apple-Origin Flies Western apple-origin flies from Skamania, WA were tested in flight tunnel assays to the Red Delicious adsorbent extract, the eastern apple blend, a candidate 10-component blend (WA1) that was based on initial GC-EAD evaluations, as well as to a series of blends (WA2-5) in which certain volatiles were subtracted (Fig. 2). Because all of the volatiles in the previously identified eastern apple blend also displayed EAD activity with western flies, we focused our subtraction tests on volatiles unique to the western flies. Western apple-origin flies displayed only moderate levels of upwind flight to the

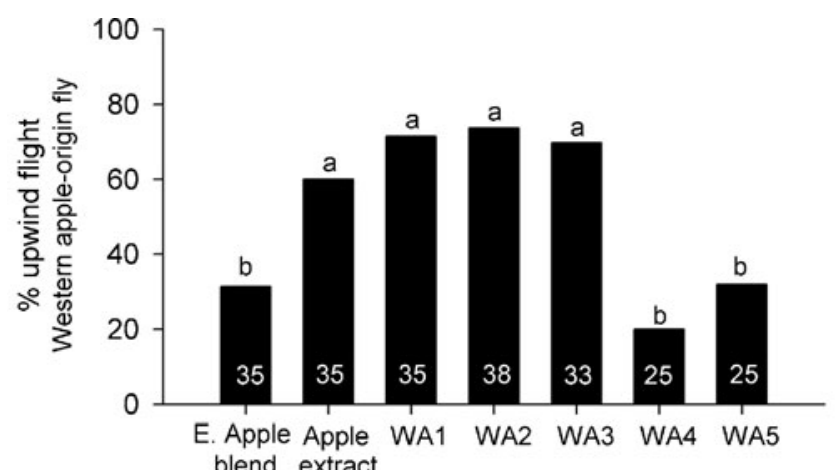

\begin{tabular}{|c|c|c|c|c|c|c|}
\hline Pentyl acetate & & 2 & 2 & & & \\
\hline Butyl butanoate & 10 & 5 & 5 & 5 & 5 & 5 \\
\hline Hexyl acetate & & 20 & 20 & 20 & 20 & \\
\hline Propyl hexanoate & 4 & 2 & 2 & 2 & 2 & 2 \\
\hline Hexyl propionate & & 4 & 4 & 4 & & 4 \\
\hline 2MB2MB & & 4 & & & & \\
\hline Butyl hexanoate & 37 & 20 & 20 & 20 & 20 & 20 \\
\hline Hexyl butanoate & 44 & 20 & 20 & 20 & 20 & 20 \\
\hline Pentyl hexanoate & 5 & 3 & 3 & 3 & 3 & 3 \\
\hline Hexyl hexanoate & & 20 & 20 & & & \\
\hline
\end{tabular}

Fig. 2 Upwind flight responses (\%) of western apple-origin flies to eastern apple blend, Red Delicious apple adsorbent extract, a candidate 10-component blend (WA1) that was based on initial GC-EAD evaluations, as well as to a series of blends (WA2-WA5) in which certain volatiles were subtracted. Relative ratios (\%) of volatile compounds tested are shown under the graph. Bold characters indicate the modified compounds. White letters inside the bars indicate the number of flies tested for each treatment. Different letters on the bars indicate significant differences $(P<0.05)$. 2MB2MB indicates 2-methylbutyl 2methylbutanoate eastern apple blend in the flight tunnel $(31.4 \% ; N=35)$, significantly lower compared to the adsorbent extract $(60.0 \%, N=35, P \leq 0.03$ two-tailed Fisher's exact test, $1 d f)$ or the 10-component WA1 blend $(71.4 \%, N=35, P \leq 0.002$, $1 d f$ ). There was no significant decrease in upwind flight levels when either 2-methylbutyl 2-methylbutanoate (WA2 = $73.7 \%, N=38$ ) or the combination of 2-methylbutyl 2- methylbutanoate + pentyl acetate + hexyl hexanoate (WA3 $=69.7 \%$, $N=33$ ) were removed from the WA1 blend. However, levels of upwind flight were reduced when either hexyl propionate (WA4 $=20.0 \%, N=25, P \leq 0.001,1 d f$ ) or hexyl acetate (WA5 $=32.0 \%, N=25, P \leq 0.004,1 d f$ ) was removed from the active 7-component WA3 blend (Fig. 2). These results indicate that the 7-component WA3 blend provided maximal levels of behavioral activity. We hereafter designate WA3 as the new "western apple" blend.

\section{Behavioral Responses of Western Black Hawthorn-Origin} Flies Western black hawthorn-origin flies reared to adulthood from infested C. douglasii fruit collected from Skamania, WA were tested in flight tunnel assays to the whole black hawthorn fruit adsorbent extract, to a candidate 11component synthetic blend (BH1) based on initial GC-EAD evaluations, as well as to a series of blends (BH2-7) in which individual components were subtracted from the 11component blend (Fig. 3). Western black hawthorn-origin flies displayed similar and non-significantly different levels

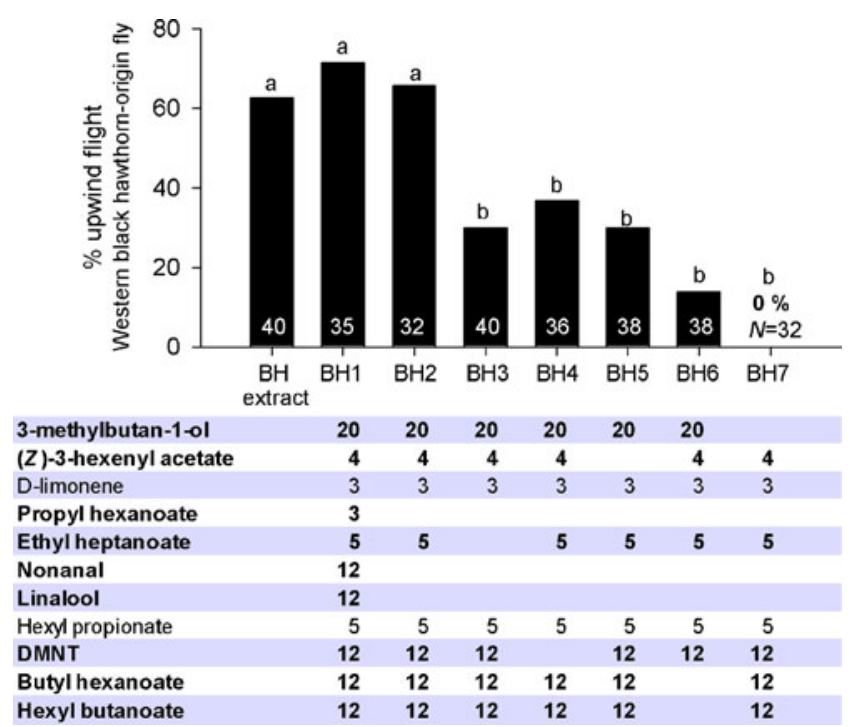

Fig. 3 Upwind flight responses (\%) of western black hawthorn-origin flies to black hawthorn adsorbent extract, a candidate 11-component blend (BH1) that was based on initial GC-EAD evaluations, as well as to a series of blends (BH2-BH7) in which certain volatiles were subtracted. Relative ratios (\%) of volatile compounds tested are shown under the graph. Bold characters indicate the modified compounds. White letters inside the bars indicate the number of flies tested for each treatment. Different letters on the bars indicate significant differences $(P<0.05)$. DMNT indicates (3E)-4,8-dimethyl-1,3,7-nonatriene 
of upwind flight to the adsorbent extract $(62.5 \%, N=40)$ compared with the 11-component BH1 blend $(71.4 \%$, $N=35$ ). Removal of the compounds propyl hexanoate, nonanal, and linalool resulted in an 8-component blend (BH2) that was not significantly different from the upwind-directed flight levels to the whole fruit extract or BH1 $(65.6 \%$, $N=32$ ). Removal of ethyl heptanoate (BH3), DMNT (BH4), or (Z)-3-hexenyl acetate (BH5) from blend $\mathrm{BH} 2$ resulted in 7-component mixtures that were significantly lower in upwind directed flight response levels compared to $\mathrm{BH} 2$ ( $\mathrm{BH} 3=30.0 \%, N=40, P \leq 0.004,1 d f ; \mathrm{BH} 4=36.8 \%$, $N=38, P \leq 0.03,1 d f$; BH5 $=30.0 \%, N=40, P \leq 0.004,1 d f$ ), but were not significantly different from each other. Removal of both butyl hexanoate and hexyl butanoate (BH6) from blend $\mathrm{BH} 2$ resulted in significantly lower response levels compared with all other blends $(13.9 \%, N=36)$. Finally, removal of 3-methylbutan-1-ol (BH7) from blend $\mathrm{BH} 2$ resulted in complete loss of upwind flight activity $(N=32)$. These results indicate that the 8-component $\mathrm{BH} 2$ blend provided maximal levels of behavioral activity. We hereafter designate $\mathrm{BH} 2$ as the new "black hawthorn" blend.

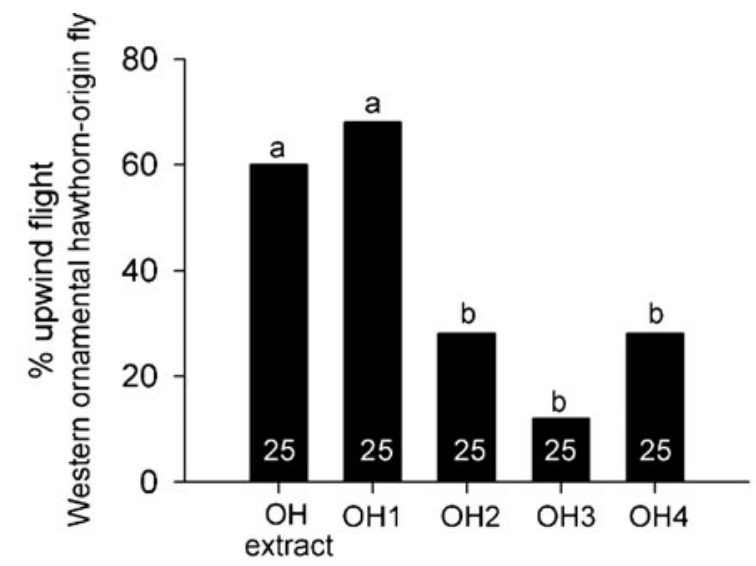

$\begin{array}{lrrrr}\text { 3-methylbutan-1-ol } & 10 & 10 & 10 & 10 \\ \text { Isoamyl propionate } & 1 & 1 & 1 & 1 \\ \text { Isoamyl isobutanoate } & 1 & 1 & 1 & 1 \\ \text { Isoamyl butanoate } & 1 & 1 & 1 & 1 \\ \text { Pentyl butanoate } & 2 & 2 & 2 & 2 \\ \text { Hexyl propionate } & 3 & 3 & 3 & 3 \\ \text { DMNT } & \mathbf{4} & \mathbf{4} & \mathbf{4} & \\ \text { Hexyl isobutanoate } & \mathbf{4 0} & & \mathbf{4 0} & \mathbf{4 0} \\ \text { Hexyl butanoate } & \mathbf{3 8} & \mathbf{3 8} & & \mathbf{3 8}\end{array}$

Fig. 4 Upwind flight responses (\%) of western ornamental hawthornorigin flies to ornamental hawthorn adsorbent extract, a candidate 9component blend $(\mathrm{OH} 1)$ that was based on initial GC-EAD evaluations, as well as to a series of blends $(\mathrm{OH} 2-\mathrm{OH} 4)$ in which certain volatiles were subtracted. Relative ratios (\%) of volatile compounds tested are shown under the graph. Bold characters indicate the modified compounds. White letters inside the bars indicate the number of flies tested for each treatment. Different letters on the bars indicate significant differences $(P<0.05)$. DMNT indicates $(3 E)$-4,8-dimethyl1,3,7-nonatriene
Behavioral Responses of Western Ornamental HawthornOrigin Flies Western ornamental hawthorn-origin flies $(N=25)$ reared to adulthood from infested $C$. monogyna fruit collected from Puyallup, WA, were tested in flight tunnel assays to the ornamental hawthorn whole fruit extract, to a 9component synthetic blend $(\mathrm{OH} 1)$ that was based on initial GC-EAD evaluations, as well as a series of three other blends in which one of the compounds in $\mathrm{OH} 1$ was removed (Fig. 4). There was no significant difference in upwind-directed flight between the 9-component $\mathrm{OH} 1$ blend $(68.0 \%, N=25)$ and whole ornamental hawthorn fruit adsorbent extract $(60.0 \%$, $N=25)$. When hexyl isobutanoate (OH2), hexyl butanoate (OH3), or DMNT (OH4) was removed singly from the 9component blend, upwind flight levels were lower compared with $\mathrm{OH} 1(\mathrm{OH} 2=28.0 \%, N=25, P \leq 0.01,1 d f ; \mathrm{OH} 3=12 \%$, $N=25, P \leq 0.001,1 d f$; $\mathrm{OH} 4=28.0 \%, N=25, P \leq 0.01,1 d f)$. These results indicate that the 9-component $\mathrm{OH} 1$ blend provided maximal levels of behavioral activity. We hereafter designate $\mathrm{OH} 1$ as the new "ornamental hawthorn" blend.

\section{Discussion}

We have now identified and developed synthetic volatile blends for western black hawthorn (C. douglasii) and ornamental hawthorn (C. monogyna) fruit using GC-EAD analyses of SPME and adsorbent samples. Western black hawthorn and ornamental hawthorn-origin flies displayed a high level of upwind directed flight to their respective natal fruit volatile blends equivalent to levels observed to their natal whole fruit adsorbent extracts, supporting the conclusion that the blends contain the full complement of compounds inducing oriented flight behavior. The black and ornamental hawthorn blends shared four compounds in common including 3-methylbutan1-ol, which appears to be a key volatile for all $R$. pomonella populations that show a preference for hawthorn fruit (Linn et al., 2003; Cha et al., 2011a,b). However, the blends also differed from one another and from the eastern and western domesticated apple blends in several respects. These differences make it possible that western $R$. pomonella may behaviorally discriminate among fruit volatiles and form ecologically differentiated host races, as is the case for eastern apple and hawthorn-infesting flies (Linn et al., 2003).

An important finding in the current study bearing on the origin of western $R$. pomonella populations was that apple flies from the western and eastern USA differed in their responses to apple fruit volatiles. A previous field study suggested that the standard five-component eastern apple blend of Zhang et al. (1999) might not be as attractive to western flies as to eastern flies (Yee et al., 2005). Here, we show that western apple-origin flies required the addition of two compounds to the eastern apple blend (hexyl acetate and hexyl propionate) to achieve a similar level of 
behavioral response in the flight tunnel as eastern appleorigin flies did to the eastern apple blend. Apple volatile profiles from the eastern and western USA did not appear to differ greatly from one another. Yet flies from these two regions clearly behaved differently.

One possible explanation for the difference is that during the introduction of apple flies from the east, a population founder effect and genetic bottleneck occurred that altered the behavior of western apple flies. A portion of the eastern apple fly population did orient to both the eastern and western apple blends. It is, therefore, conceivable that these flies disproportionately contributed to the establishment of apple flies in the west. An alternative possibility is that western apple-origin flies may not represent an introduction from the east at all, but instead a recent host shift from either black or ornamental hawthorn to apple. In this case, the difference between eastern and western apple flies would result from the independent evolution of behavioral discrimination for apple fruit volatiles from different ancestral hawthorn populations.

Genetic data could help resolve whether eastern and western apple fly populations formed independently in different regions of the country, or represent a single host shift in the East followed by an introduction to the West (McPheron, 1990). For example, it may be that western and eastern fly populations that infest apples and hawthorn possess unique alleles that distinguish them from each other and thus support the independent origins hypothesis. However, it is also possible that black hawthorn-origin flies are native to the west, and apple-origin flies were introduced. In this case, local gene flow from black hawthorn-origin flies could mask the genetic signature of the introduction.

Future behavioral studies of $R$. pomonella's behavioral responses to natal and non-natal fruit volatile blends also could help clarify the origins of western fly populations, along with their host race status. For example, if western black hawthorn and ornamental hawthorn-origin flies show high levels of upwind flight to the western, but not to the eastern, apple blend comparable to levels they display to their natal hawthorn blends, then this would argue against both western host races and an introduction of apple flies to the Pacific Northwest. Instead, it would suggest that western apple flies arose from a recent host shift from black and/or ornamental hawthorn-origin fly populations. It also is possible that black hawthorn and ornamental hawthorn-origin flies show little interest in both the western and eastern apple blends. Such a finding would be consistent with black hawthorn-origin flies being native and giving rise to the ornamental hawthorn fly population, while western apple flies were introduced. Finally, it is possible that all the western fly populations differ from one another in their response patterns, thus making it difficult to resolve their evolutionary origins, but implying that they represent at least partially ecologically reproductively isolated host races. Regardless, the development of black hawthorn, ornamental hawthorn, and western apple fruit volatile blends now puts us in position to test these hypotheses and further investigate the intriguing story of western $R$. pomonella to assess their evolutionary significance and threat to commercial apple orchards in the Pacific Northwest.

Acknowledgments We thank Mike Chong at the University of Waterloo, Ontario, Canada, for the synthesis of DMNT. We thank Tracy Arcella, Stewart Berlocher, Scott Egan, Andrew Forbes, Glen Hood, Dave Costello, H. W. Jackson, and Jim Stevens for help in collecting fruit and fly samples, thoughtful discussion, and/or assistance in helping us prepare the manuscript for publication. We thank Blair Wolfley, Washington State University, Vancouver, and Clark County, WA General Services, for providing storage and rearing facilities. We acknowledge Meralee Nash for collection of fruit and rearing of larvae from Puyallup. We thank Callie Musto, Kathy Poole, and Paula Fox for maintaining the flies received from Notre Dame and Yakima, and Harvey Reissig, Cynthia Smith, and Dave Combs for use of the Geneva, New York, apple maggot colony. The research was supported by grants to J.L.F. and C.E.L. from the National Science Foundation (\#0614378) to J.L.F. from the USDA, and to W.L.Y. from the Washington Tree Fruit Research Commission and Washington State Commission on Pesticide Registration.

\section{References}

AliniaZee, M. T. and Penrose, R. L. 1981. Apple maggot in Oregon: possible new threat to the Northwest apple industry. Bull. Entomol. Soc. Amer. 27:245-246.

AliniazeE, M. T. and Westcott, R. L. 1987. Flight period and seasonal development of the apple maggot, Rhagoletis pomonella (Walsh) (Diptera, Tephritidae) in Oregon. Ann. Entomol. Soc. Amer. 80:823-828.

Berlocher, S. H. and Feder, J. L. 2002. Sympatric speciation in phytophagous insects: Moving beyond controversy? Annu. Rev. Entomol. 47:773-815.

Berlocher, S. H., McPheron, B. A., Feder, J. L., and Bush, G. L. 1993. A revised phylogeny of the Rhagoletis pomonella (Diptera: Tephritidae) sibling species group. Ann. Entomol. Soc. Amer. 86:716-727

BRUNNER, J. F. 1987. Apple maggot in Washington state: A review with special reference to its status in other Western States. Meladeria 45:33.

Bush, G. L. 1966. The Taxonomy, Cytology, and Evolution of the genus Rhagoletis in North America (Diptera: Tephritidae). Museum of Comparative Zoology, Cambridge, MA.

BusH, G. L. 1969. Sympatric host race formation and speciation in frugivorous flies of genus Rhagoletis (Diptera: Tephritidae). Evolution 23:237.

Cha, D. H., Powell, T. H. Q., Feder, J. L., and LinN, C. E. JR. 2011 a. Identification of host fruit volatiles from mayhaw species $(\mathrm{Cra}$ taegus SERIES aestivales) host plants attractive to mayhaworigin Rhagoletis pomonella flies in the southern United States. J. Chem. Ecol. 37:961-973.

ChA, D. H., POWEll, T. H. Q., Feder, J. L., and LinN, C. E. JR. 2011 b. Identification of host fruit volatiles from green hawthorn (Crataegus viridis) and blueberry hawthorn (C. brachyacantha) host plants attractive to different phenotypes of Rhagoletis pomonella flies in the southern United States. J. Chem. Ecol. 37:974-983.

Coyne, J. A. and ORR, H. A. 2004. Speciation. Sinauer Associates, Sunderland, MA. 
DAmbroski, H. R. and Feder, J. L. 2007. Host plant and latituderelated diapause variation in Rhagoletis pomonella: A test for multifaceted life history adaptation on different stages of diapause development. J. Evol. Biol. 20:2101-2112.

Dambroski, H. R., LinN, C. E. JR., Feder, J. L., Berlocher, S. H., NoJIMA, S., and RoELOFS, W. L. 2005. The genetics of fruit odor discrimination in Rhagoletis pomonella flies and its implications for sympatric host race formation and speciation. Evolution 59:1953-1964.

FEDER, J. L. 1998. The apple maggot fly, Rhagoletis pomonella: Flies in the face of conventional wisdom? pp 130-144, in D. J. Howard and S. H. Berlocher (eds.), Endless Forms: Species and Speciation. Oxford University Press, Oxford.

FEDER, J. L. and ForBES, A.A. 2007. Habitat avoidance and speciation for phytophagous insect specialists. Funct. Ecol. 21:585-597.

FEDER, J. L. and ForBES, A.A. 2008. Host fruit-odor discrimination and sympatric host-race formation. in K. J. Tilmon (ed.), The Evolutionary Biology of Herbivorous Insects: Specialization, Speciation, and Radiation. University of California Press, Berkley, CA.

Feder, J. L., Opp, S. B., Wlazlo, B., Reynolds, K., Go, W., and SPISAK, S. 1994. Host fidelity is an effective premating barrier between sympatric races of the apple maggot fly. Proc. Natl. Acad. Sci. USA 91:7990-7994.

FeIN, B. L., ReISSIG, W. H., and Roelofs, W. L. 1982. Identification of apple volatiles attractive to the apple maggot. J. Chem. Ecol. 8:1473-1487.

Forbes, A. A., Fisher, J., and FEDER, J. L. 2005. Habitat avoidance: Overlooking an important aspect of host-specific mating and sympatric speciation? Evolution 59:1552-1559.

Forbes, A. A. and FEDER, J. L. 2006. Divergent preferences of Rhagoletis pomonella host races for olfactory and visual cues. Entomol. Exp. App. 119:121-127.

FunK, D. J., FILCHAK, K. E., and Feder, J. L. 2002. Herbivorous insects: model systems for the comparative study of speciation ecology. Genetics 116:251-267.

GreEnWALD, R., Chaykovsky, M., and COREY, E. J. 1963. The Wittig reaction using methylsulfinyl carbanion-dimethyl sulfoxide. $J$. Org. Chem. 28:1128-1129.

LINN, C. E. JR., FEDER, J. L., NOJIMA, S., DAMBROSKI, H. R., BERLOCHER, S. H., and Roelofs, W. L. 2003. Fruit odor discrimination and sympatric host race formation in Rhagoletis. Proc. Natl. Acad. Sci. USA 100:11490-11493.

LinN, C. E. JR., DAmbroski, H. R., Feder, J. L., Berlocher, S. H., NoJIMA, S., and Roelofs, W. L. 2004. Postzygotic isolating factor in sympatric speciation in Rhagoletis flies: reduced response of hybrids to parental host-fruit odors. Proc. Natl. Acad. Sci. USA 101:17753-17758.

LinN, C. E. JR., NoJIMA, S., and Roelofs, W. L. 2005a. Antagonist effects of non-host fruit volatiles on discrimination of host fruit by
Rhagoletis flies infesting apple (Malus pumila), hawthorn (Crataegus spp.), and flowering dogwood (Cornus florida). Entomol. Exp. Appl. 114:97-105.

Linn, C. E. JR., DAmbroski, H., NoJima, S., Feder, J. L., Berlocher, S. H., and ROELOFS, W. L. 2005b. Variability in response specificity of apple, hawthorn, and flowering dogwood-infesting Rhagoletis flies to host fruit volatile blends: implications for sympatric host shifts. Entomol. Exp. Appl. 116:55-64.

MCPHERON, B. A. 1990. Genetic-structure of the apple maggot fly (Diptera: Tephritidae) populations. Ann. Entomol. Soc. Amer. 83:568-577.

National Agricultural Statistics Service 2009. Apples, Washington. U.S. Department of Agriculture. Washington Field Office. www. nass.usda.gov.

Neilson, W. T. A. and Mcallan, J. W. 1965. Artificial diets for apple maggot 3. Improved defined diets. J. Econ. Entomol. 58:542.

NoJima, S., LinN, C. E., JR., Zhang, A., Morris, B., and Roelofs, W. L. 2003a. Identification of host fruit volatiles from hawthorn (Crataegus spp.) attractive to hawthorn-origin Rhagoletis pomonella flies. J. Chem. Ecol. 29:319-334.

NoJIMA, S., LinN, C. E., JR., ZHANG, A., Morris, B., and RoElofs, W. L. 2003b. Identification of host fruit volatiles from flowering dogwood (Cornus florida) attractive to dogwood-origin Rhagoletis pomonella flies. J. Chem. Ecol. 29:2347-2357.

Prokopy, R. J., Bennett, E. W., and Bush, G. L. 1971. Mating behavior in Rhagoletis pomonella (Diptera: Tephritidae). I. Site of assembly. Can. Entomol. 103:1405-1409.

Prokopy, R. J., BennetT, E. W., and Bush, G. L. 1972. Mating behavior in Rhagoletis pomonella (Diptera: Tephritidae). II. Temporal organization. Can. Entomol. 104:97-104.

Tracewski, K. T., Brunner, J. F., Hoyt, S. C., and Dewey, S. R. 1987. Occurrence of Rhagoletis pomonella (Walsh) in hawthorns, Crataegus, of the Pacific Northwest (USA). Melanderia 45:19-25.

YEE, W. L. 2008. Host plant use by apple maggot, western cherry fruit fly, and other Rhagoletis species (Diptera:Tephritidae) in central Washington state. Pan. Pac. Entomol. 84:163-178.

YeE, W. L. and Goughnour, R. B. 2008. Host plant use by and new host records of apple maggot, western cherry fruit fly, and other Rhagoletis species (Diptera: Tephritidae) in western Washington state. Pan. Pac. Entomol. 84:179-183.

YeE, W. L., LANDOLT, P. J., and DARNELl, T. J. 2005. Attraction of Rhagoletis pomonella (Diptera: Tephritidae) and nontarget flies to traps baited with ammonium carbonate and fruit volatile lures in Washington and Oregon. J. Agr. Urb. Entomol. 22:133-149.

Zhang, A., LinN, C. E. Jr., Wright, S., Prokopy, R., Reissig, W., and RoELOFS, W. L. 1999. Identification of a new blend of apple volatiles attractive to the apple maggot, Rhagoletis pomonella. $J$. Chem. Ecol. 25:1221-1232. 